\title{
Highly sensitive and rapid gas biosensor for formaldehyde based on an enzymatic cycling system
}

\author{
Akira Monkawa $^{\mathrm{a}, *}$, Tomoko Gessei ${ }^{\mathrm{a}}$, Yuki Takimoto ${ }^{\mathrm{a}}$, Nobuaki Jo ${ }^{\mathrm{a}}$, \\ Toshiaki Wada $^{\mathrm{b}}$, Nobuyuki Sanari ${ }^{\mathrm{b}}$ \\ ${ }^{a}$ Tokyo Metropolitan Industrial Technology Research Institute, 2-4-10, Aomi, Kotoku, \\ Tokyo 135-0064, Japan \\ ${ }^{b}$ Sibata Scientific Technology LTD, 1-1-62, Nakane, Soka-City, Saitama, Japan
}

E-mail: monkawa.akira@iri-tokyo.jp

Fax: $+81-3-5530-2629$ 


\section{Abstract}

An enzymatic cycling system for detecting formaldehyde in water and indoor environments has been developed. The system is based on both the dehydrogenation of formaldehyde and the reduction of nicotinamide adenine dinucleotide $\left(\mathrm{NAD}^{+}\right)$in the presence of formaldehyde dehydrogenase. NADH generated in the reaction then reduces 4-[3-(2-methoxy-4-nitrophenyl)-2-(4-nitrophenyl)-2H-5-tetrazolio]-1,3-benzene disulfonate sodium salt (WST-8) to yellow WST-8 formazan in the presence of enzyme diaphorase. The quantity of formaldehyde can be detected by the color change resulting from the formation of WST-8 formazan. The assay solution was optimized with respect to the $\mathrm{pH}$, type of buffer, and enzyme and WST- 8 concentrations. The limit of detection for formaldehyde in water was found to be $10 \mathrm{ppb}$ after $3 \mathrm{~min}$. The assay solution also displayed a highly selective response to formaldehyde over other pollutant gases present in indoor air. In addition, formaldehyde gas was detected after bubbling prepared formaldehyde/air mixtures with known formaldehyde concentrations in assay solutions. The limit of detection for formaldehyde gas was $1.5 \mathrm{ppb}$ after $5 \mathrm{~min}$. This system can quickly and accurately detect low concentration of formaldehyde in water and gas. 
Keywords:

Enzymatic cycling system

WST-8 formazan

formaldehyde dehydrogenase

Formaldehyde 


\section{Introduction}

Formaldehyde, the simplest aldehyde, is a colorless gaseous organic compound that is used as a preservative in cosmetics and in the production of resins in wood products, vinyl flooring, and other plastics. The International Agency for Research on Cancer classified formaldehyde as a Group-1 carcinogen based on evidence in humans of nasopharyngeal cancer and studies on the carcinogenicity of auramine in humans and animals [1]. Exposure to formaldehyde can cause many potential health risks, such as central nervous system damage, immune system disorders, asthma, and nasopharyngeal cancer [2-4]. According to the World Health Organization (WHO) guidelines for residential indoor air quality, the formaldehyde exposure limit is defined as $80 \mathrm{ppb}$ [5]. This criterion is insufficient for asthma among young children, however, because the risk of asthma increases due to the chronic aspiration of formaldehyde even at levels below $50 \mathrm{ppb}[6]$.

In 2012, relatively high concentrations of formaldehyde (>80 ppb) were detected in drinking water at water purification plants in Japan. The high concentrations of formaldehyde were attributed to the presence of hexamethylenetetramine in industrial waste water, which reacted with chlorine used as a disinfectant. The detection led to the suspension of water supply, affecting many residents that receive water from these 
plants.

This example demonstrates why the analysis of ppb levels of formaldehyde in gases and liquids is an important technology for atmospheric environmental measurement and control. High-performance liquid chromatography (HPLC) and gas chromatography-mass spectrometry (GC-MS) are accurate qualitative and quantitative analytical methods for detecting low concentrations of formaldehyde [7]. However, HPLC and GC-MS cannot be performed onsite, and often these methods involve lengthy analysis times.

Detector tubes, chemical sensors and optical sensors are the most widely used methods for detecting formaldehyde [8-11]. These devices have high portability, but lack rapidity and selectivity [12]. Biosensors based on enzyme-catalyzed dissolution have improved rapidity and selectivity [13-19], and biosensors for detecting formaldehyde have been based on the reaction of a nicotinamide adenine dinucleotide $\left(\mathrm{NAD}^{+}\right)$-dependent dehydrogenase enzyme using different mediators for NADH electro-oxidation, either in batch reactors or under flow conditions [20-22]. The concentration of formaldehyde can be determined from the quantity of NADH produced, which can be measured based on its absorbance at $339 \mathrm{~nm}$ or fluorescence at $470 \mathrm{~nm}$ [23-25]. However, the sensitivity of such methods is insufficient due to the low 
extinction coefficient and weak fluorescence of NADH [26].

In contrast, enzymatic cycling systems are highly sensitive. In such systems, the target metabolite is regenerated via two enzymatic reactions occurring in the opposite directions. In addition, the quantity of the target metabolite can be detected using colorimetric analysis. For example, tetrazolium salts produce highly colored formazan dyes upon NADH reduction, and thus enzymatic cycling system assays using these salts are based on the colorimetric quantification of NADH. In particular, 4-[3-(2-methoxy-4-nitrophenyl)-2-(4-nitrophenyl)-2H-5-tetrazolio]-1,3-benzene disulfonate sodium salt (WST-8) is a water soluble tetrazolium salt with high stability and high sensitivity [27]. A WST-8 cell proliferation assay based on an enzymatic cycling system has been developed for monitoring cell proliferation and cytotoxicity using a spectrophotometer [28]. Colorimetric assays based on enzymatic cycling systems have also been applied to detect minor components in drugs and food substances because of their greater sensitivity and accuracy compared to NADH fluorescent methods $[29,30]$.

Herein is described a highly sensitive and accurate formaldehyde biosensor based on an enzymatic cycling system. This sensor can detect formaldehyde in both water and indoor air. The mechanism of the assay is shown in Scheme 1. NAD is hydrogenated to 
$\mathrm{NADH}$, while formaldehyde is simultaneously oxidized to formic acid by formaldehyde dehydrogenase (FALDH). The NADH is then dehydrogenated to $\mathrm{NAD}^{+}$during the enzymatic cycling reaction of diaphorase (DI), which employs the tetrazolium salt WST-8 to produce water-soluble, yellow WST-8 formazan. The concentration of formaldehyde can be calculated based on the change in the absorbance of WST-8 formazan at $460 \mathrm{~nm}$. 


\section{Experimental}

\subsection{Reagents and chemicals}

WST-8 was purchased from Dojindo Laboratories (Kumamoto, Japan). FALDH (FALDH, EC 1.2.1.46, 1 unit/mg protein, solid, from Pseudomonas sp.) and DI (EC 1.6.99., 30 units/mg protein, from Clostridium sp.) were purchased from Toyobo (Osaka, Japan). $\mathrm{NAD}^{+}$was obtained from Wako Pure Chemical Industries (Osaka, Japan). Ethylenediaminetetraacetic acid disodium salt dihydrate (EDTA) was obtained from Sigma Aldrich (St Louis, MO). All the reagents were of analytical-reagent grade and were used without further purification. All solutions were prepared with water purified using a Milli-Q system (Millipore, Tokyo, Japan).

\subsection{Preparation of assay solutions and the analytical method for formaldehyde in} water

First, to determine the $\mathrm{pH}$ dependence of the assay solution, the change in the conversion ratio of WST-8 was examined at $\mathrm{pH}$ values ranging from 7.0 to 10.0 using $100 \mathrm{mM}$ phosphate ( $\mathrm{pH} 7.0,7.5$, and 8.0), $100 \mathrm{mM}$ tris- $\mathrm{HCl}(\mathrm{pH} \mathrm{8.0,} \mathrm{8.5,} \mathrm{and} \mathrm{9.0),} 100$ $\mathrm{mM}$ borate $(\mathrm{pH} 8.0,8.5$, and 9.0), and $100 \mathrm{mM}$ carbonate $(\mathrm{pH} 9.5$ and 10.0) buffer solutions. The formaldehyde concentration in these solutions was fixed at $0.033 \mathrm{mM}$, which corresponds to a formalin concentration of $1 \mathrm{ppm}$. The assay solutions were 
prepared by dissolving $\mathrm{NAD}^{+}(0.3 \mathrm{mM})$, WST-8 $(0.3 \mathrm{mM})$, EDTA $(0.1 \mathrm{mM})$, DI $(1$ $\mathrm{U} / \mathrm{ml})$, and FALDH $(1 \mathrm{U} / \mathrm{ml})$ in different buffer solutions.

To optimize the concentration of DI, solutions containing DI concentrations ranging from 0 to $1.0 \mathrm{U} / \mathrm{ml}$ were prepared by dissolving $\mathrm{NAD}^{+}(0.3 \mathrm{mM})$, WST-8 $(1 \mathrm{mM})$, EDTA $(0.1 \mathrm{mM})$, and FALDH $(1 \mathrm{U} / \mathrm{ml})$ in the $100 \mathrm{mM}$ phosphate buffer solution $(\mathrm{pH}$ 8.0). The effect of DI concentration on the absorbance of the solutions was then determined.

To optimize the concentration of FALDH, solutions containing FALDH concentrations ranging from 0 to $1.0 \mathrm{U} / \mathrm{ml}$ were prepared by dissolving $\mathrm{NAD}^{+}(0.3 \mathrm{mM})$, WST- $8(1 \mathrm{mM})$, EDTA $(0.1 \mathrm{mM})$, and DI $(1 \mathrm{U} / \mathrm{ml})$ in the $100 \mathrm{mM}$ phosphate buffer solution ( $\mathrm{pH}$ 8.0). The effect of FALDH concentration on the absorbance of the solutions was then determined.

To observe the effect of WST-8 on the absorbance, solutions with WST-8 concentrations ranging from 0 to $1.0 \mathrm{mM}$ were prepared by dissolving $\mathrm{NAD}^{+}(0.3 \mathrm{mM})$, EDTA $(0.1 \mathrm{mM})$, FALDH $(1 \mathrm{U} / \mathrm{ml})$, and DI $(1 \mathrm{U} / \mathrm{ml})$ in the $100 \mathrm{mM}$ phosphate buffer solution ( $\mathrm{pH} 8.0)$.

A calibration curve was prepared and the selectivity for formaldehyde was also evaluated using assay solution consistings of NAD ${ }^{+}(0.3 \mathrm{mM})$, WST-8 $(1 \mathrm{mM})$, EDTA 
(0.1 mM), and DI (1 U/ml) in the $100 \mathrm{mM}$ phosphate buffer solution $(\mathrm{pH} 8.0)$. Each data point was an average of five measurements. To establish the calibration curve, solutions with formaldehyde concentrations ranging from 5 to $500 \mathrm{ppb}$ were prepared and their absorbances were determined. To evaluate the selectivity of the biosensor, the absorbance of solutions containing $1 \mathrm{ppm}$ of different organic solvents were measured.

In all the experiments, the reaction mixture was incubated at $25^{\circ} \mathrm{C}$ for $3 \mathrm{~min}$. During this process, the change in absorbance was measured at $460 \mathrm{~nm}$ using spectroscopic system. The cell folder was connected to the spectrometer and the light source through $100 \mu \mathrm{m}$ optical fibers. The light source was a tungsten halogen lamp (LS-1, Ocean Optics) optimized for the visible-NIR (VIS-NIR) range $(360-2500 \mathrm{~nm})$. The absorbance was measured using a UV-Visible spectrophotometer (USB2000, Ocean Optics).

\subsection{Detection of formaldehyde gas using the enzymatic cycling system}

To evaluate the performance of the enzymatic cycling system for detecting formaldehyde in gas samples, a vapor generation system was fabricated to provide variable formaldehyde gas concentrations. Dry air (humidity $<1 \%$ ) generated using a clean air unit (P4-QD10, IAC) was employed as the base gas in the sensing system. Air samples with low concentrations of formaldehyde (5-80 ppb) were obtained using a 
standard gas generation system (Permeater PD-1B-2, GASTEC) based on the diffusion method.

The detection of formaldehyde gas by the sensor was investigated using an assay solution consisting of $\mathrm{NAD}^{+}(0.3 \mathrm{mM})$, WST-8 $(1 \mathrm{mM})$, EDTA $(0.1 \mathrm{mM})$, and DI (1 $\mathrm{U} / \mathrm{ml}$ ) dissolved in the $100 \mathrm{mM}$ phosphate buffer solution ( $\mathrm{pH} \mathrm{8.0).} \mathrm{Figure} 1$ shows the schematic diagram of the bubbling system used to introduce the formaldehyde/air gas mixture in the assay solution. The flow rate of the sample gas was controlled using a mass flow controller (MODEL8500, KOFLOC). After bubbling the sample gas for 5 min, the assay solution was transferred to a quartz cell for spectroscopic analysis. Each data point represents the average of 5 measurements. 


\section{Results and Discussion}

\subsection{Optimization of the assay solution}

The enzymatic cycling system consists of the cycling reaction of the two enzymes, i.e., FALDH and DI. In such systems, the sensitivity increases as the number of cycles increases. Therefore, identifying the optimum conditions for achieving a maximum cycling rate is important. The cycling rate depends on the concentrations of WST-8, FALDH, and DI, as well as the reaction $\mathrm{pH}$ and time.

The optimal $\mathrm{pH}$ range for the enzymatic cycling system was evaluated using phosphate ( $\mathrm{pH} 7.0,7.5$, and 8.0), tris- $\mathrm{HCl}(\mathrm{pH} 8.0,8.5$, and 9.0), borate $(\mathrm{pH} \mathrm{8.0,} \mathrm{8.5,}$ and 9.0), and carbonate (pH 9.5 and 10.0) buffer solutions. Figure 2 shows the $\mathrm{pH}$ dependence of these different assay solutions. In the phosphate buffer, the absorbance increased with increasing $\mathrm{pH}$ and reached approximately 1.4 at $\mathrm{pH} 8.0$. In the borate buffer, the absorbance drastically decreased with increasing $\mathrm{pH}$, and similar to the phosphate buffer, the maximum absorbance was observed at $\mathrm{pH}$ 8.0. In the tris- $\mathrm{HCl}$ buffer, the absorbance was less than 0.1 regardless of $\mathrm{pH}$, while in the carbonate buffer, the absorbance was approximately 1.2 at $\mathrm{pH}$ values of 9.5 and 10.0 .

The sensitivity of WST- 8 and the activity of DI and FALDH depend on the solution $\mathrm{pH}$. Both the sensitivity and the yield of WST-8 remain nearly unchanged at $\mathrm{pH}$ values 
above 8.0 [31]. FALDH is also stable at $\mathrm{pH} 8.0-10.0$, but its activity is the highest at $\mathrm{pH}$ 9.0 [32]. Although DI is stable at $\mathrm{pH} 7.5-9.0$, the optimum $\mathrm{pH}$ has been reported to be 8.5 [33]. Therefore, based on the stability of WST-8 and the activity of the two enzymes, the optimal $\mathrm{pH}$ was expected to be 8.0-9.0. The results of the $\mathrm{pH}$ dependence studies were contrary to such expectations. To reveal the reason for this discrepancy, the rate of the enzymatic reaction was observed in several buffer solutions.

Figure 3 shows the kinetic curves in the borate $(\mathrm{pH} \mathrm{8.0,8.5,} \mathrm{and} \mathrm{9.0)} \mathrm{and} \mathrm{tris-} \mathrm{HCl}$ ( $\mathrm{pH} 8.0,8.5$, and 9.0) buffer solutions. In the borate buffer, the maximum absorbance was reached within $3 \mathrm{~min}$ at $\mathrm{pH} 8.0,10 \mathrm{~min}$ at $\mathrm{pH} 8.5$, and $30 \mathrm{~min}$ at $\mathrm{pH} 9.0$, and the maximum absorbance values were 1.3-1.4. It can be seen in the figure that the rate of the enzymatic reaction decreased as the $\mathrm{pH}$ of the borate buffer increased. The lower absorbance at $\mathrm{pH} 8.5$ and 9.0 in the borate buffer is attributed to the insufficient reaction time of $3 \mathrm{~min}$ for the color measurement. In the tris- $\mathrm{HCl}$ buffer, on the other hand, the rate of the enzymatic reaction was very slow at all the $\mathrm{pH}$ values evaluated. The enzymatic reaction was greatly influenced by Tris(hydroxymethyl)aminomethane concentrations in the tris- $\mathrm{HCl}$ buffer [34]. This result indicates that the tris- $\mathrm{HCl}$ buffer is unsuitable as a buffer solution for the enzymatic cycling system because Tris(hydroxymethyl)aminomethan hindered the catalysis. In the phosphate and 
carbonate buffers, the maximum absorbance was generally reached within $1 \mathrm{~min}$, and the rates of the enzymatic reaction in the these two buffer solutions were considerably higher than those in the tris- $\mathrm{HCl}$ and borate buffer solutions, suggesting that the rate of the enzymatic reaction depends on the type of buffer solution. In an onsite biosensor for detecting formaldehyde in water and the atmosphere, a rapid enzymatic reaction is required. Therefore, a phosphate buffer solution at $\mathrm{pH} 8.0$ was selected as the optimum solution.

The sensitivity of the enzymatic cycling system can be increased by using larger quantities of the two enzymes, i.e., DI and FALDH. To determine the lower acceptable limits for the enzyme concentrations, the quantities of the cycling enzymes were varied while keeping the amounts of the other reagents in the solution constant. Figure $4 \mathrm{a}$ shows the effect of DI concentration on the absorbance. As can be seen in the figure, the absorbance saturated after the DI concentration increased from 0 to $0.1 \mathrm{U} / \mathrm{ml}$. It was concluded that a DI concentration of at least $0.1 \mathrm{U} / \mathrm{ml}$ was required in the assay solution. Figure $4 \mathrm{~b}$ shows the effect of FALDH concentration on the absorbance. As can be seen in this figure, the absorbance initially increased as the FALDH concentration increased and then remained constant in the range from 0.5 to $1.0 \mathrm{U} / \mathrm{ml}$. Consequently, it was determined that a FALDH concentration of at least $0.5 \mathrm{U} / \mathrm{ml}$ is required in the assay 
solution.

When designing enzymatic cycling systems, it is important to maintain a balance between the cost of the system and the rate of the reaction. The enzymes are generally the most expensive components, and therefore the quantities used should be minimized to lower the cost of the system. However, the use of insufficient quantities of the enzymes may lead to serious problems, such as incomplete cycling reactions, nonattainment of a steady state, and nonlinearity of the results with the reaction time [35]. To avoid the occurrence of such problems, the maximum evaluated concentrations of DI (1 U/ml) and FALDH (1 U/ml) were selected as the optimum concentrations.

To enhance the sensitivity of the enzymatic cycling system, it was also important to determine the optimal concentration of WST-8. Figure 4c shows the effect of the WST-8 concentration on the absorbance. These results indicate that the lower limit for the WST concentration was $0.4 \mathrm{mM}$. The conversion of WST- 8 to the highly colored WST- 8 formazan dye during the cycling reaction is an irreversible process, and thus the quantity of WST-8 declines as the cycling reaction proceeds. Because the reaction time for detecting formaldehyde in the gaseous state is longer than that in water, a WST-8 concentration of $1 \mathrm{mM}$ was selected as the optimum concentration.

\subsection{Calibration curve for formaldehyde in water}


The cycling enzymatic system was applied to detect formaldehyde in water. Aqueous solutions with formaldehyde concentrations ranging from 5 to $500 \mathrm{ppb}$ were prepared and analyzed using the above described technique. Figure 5 shows the calibration curve for the application of the enzymatic cycling system to detect formaldehyde in water. The absorbance data for seven formaldehyde concentrations were plotted, and the best-fit line was drawn through the points. This straight line has a slope $s$ of 1.56 and a

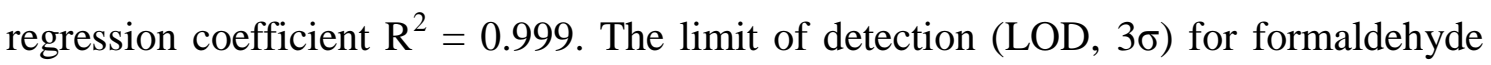
was determined to be $3.3 \mathrm{ppb}$. In practice, however, the absorbance peak is easy to recognize at absorbance values greater than 0.01 , which was calculated using the equation to be equivalent to $13 \mathrm{ppb}$. Considering the measurement inaccuracies, the practical concentration limit for detecting formaldehyde in water was $15 \mathrm{ppb}$.

\subsection{Selectivity of the assay solution}

To assess the selectivity of the formaldehyde biosensor, the response of the biosensor to assay solutions containing various added organic solvents that are often present as indoor air pollutants was examined. Figure 6 shows the absorbance results for assay solutions containing $1 \mathrm{ppm}$ each of formic acid, acetone, ethanol, and methanol. The results indicated that the assay solution has excellent selectivity for formaldehyde. The 
absorbance for acetaldehyde was 0.07 , which was only $5.3 \%$ that of the absorbance for formaldehyde, and no response to the other solvents was observed. This high selectivity for formaldehyde can be attributed to the specificity of FALDH.

\subsection{Optimization of the enzymatic cycling system for formaldehyde gas}

Formaldehyde gas can be detected by performing the enzymatic cycling reaction using an assay solution in which the air sample containing formaldehyde has been bubbled. To enhance the sensitivity of the enzymatic cycling system for detecting gaseous formaldehyde, it was necessary to optimize the volume of the assay solution, the bubbling time, and the flow rate of the formaldehyde/air gas mixture.

Figure 7a shows the relationship between the volume of the assay solution and the absorbance. The flow rate of the formaldehyde/air mixture was set to $500 \mathrm{ml} / \mathrm{min}$, and the bubbling time was $10 \mathrm{~min}$. As can be seen in the figure, the absorbance drastically increased as the volume of the assay solution decreased, indicating that the amount of formaldehyde gas that was dissolved in the assay solution increased. The best-fit line drawn through the points was represented by a power approximation expressed as $\mathrm{y}=$ $0.69 \mathrm{x}^{-0.95}$ with a correlation coefficient of 0.994 . This result suggests that a decrease in the volume of the assay solution was useful for enhancing the sensitivity of the biosensor. However, if the volume of the assay solution was less than $0.5 \mathrm{ml}$, it was 
difficult to dissolve the formaldehyde gas in the solution by bubbling. Therefore, a volume of $0.5 \mathrm{ml}$ was selected as the optimum volume for the assay solution.

Figure $7 \mathrm{~b}$ shows the relationship between the bubbling time of a formaldehyde/air mixture and absorbance. The reaction was then performed with a formaldehyde concentration of $5 \mathrm{ppb}$ using an assay volume of $0.5 \mathrm{ml}$ and a flow rate of $500 \mathrm{ml} / \mathrm{min}$. The absorbance increased linearly as the bubbling time increased from 3 to $10 \mathrm{~min}$, indicating that the cycling reaction depended on the bubbling time. The equation for the linear regression was expressed as $\mathrm{y}=0.033 \mathrm{x}-0.078$, with a correlation coefficient of 0.998. With 1 min bubbling time, the absorbance value was 0 . The recognized absorbance peak can be observed from 5 to $10 \mathrm{~min}$. Therefore, a bubbling time of $5 \mathrm{~min}$ was selected as the optimum condition.

Figure $7 \mathrm{c}$ shows the effect of the flow rate of the formaldehyde/air gas mixture on the enzymatic cycling reaction for an assay volume of $0.5 \mathrm{ml}$ and a bubbling time of $5 \mathrm{~min}$. The absorbance increased linearly as the flow rate increased, indicating that the cycling reaction depended on the flow rate. The equation for the linear regression was expressed as $y=1.24 x+0.028$, with a correlation coefficient of 0.997 . The optimized flow rate was set at $500 \mathrm{ml} / \mathrm{min}$ considering the loss of the assay solution with bubbling and the maximum flow rate of standard gas generation systems. 


\subsection{Calibration curve for formaldehyde gas}

Figure 8 shows the calibration curve for assay solutions in which formaldehyde/air mixtures with different formaldehyde concentrations (5-80 ppb) were bubbled for 5 min. The relationship between the absorbance and the formaldehyde concentration was highly linear over the entire investigated range, indicating that the enzymatic cycling reaction proceeded in proportion to the bubbling of the formaldehyde gas. The data points were fitted to a straight line, and the equation for the linear regression was expressed as $y=6.90 x+0.034$, with a correlation coefficient of 0.999 . The detection limit was estimated to be $1.5 \mathrm{ppb}$. Table 1 shows the average absorbance and relative standard deviation $(\mathrm{n}=5)$ values. The relative standard deviations were $1 \%-6.5 \%$. Importantly, at a formaldehyde concentration of $5 \mathrm{ppb}$, the relative standard deviation was 0.0047 , which was less than that of the absorbance change per $1 \mathrm{ppb}(=0.033)$ calculated from the calibration curve for formaldehyde gas. This result indicates that the enzymatic cycling system can distinguish a change in the formaldehyde gas concentration of $1 \mathrm{ppb}$, even at low formaldehyde gas concentrations. Therefore, the enzymatic cycling system should be applicable for detecting formaldehyde in indoor air at the levels mentioned in the WHO guidelines.

Finally, the calibration curves for formaldehyde in water and gas are shown together 
in Figure 9. Assuming that the formaldehyde gas was completely dissolved in the assay solution, the transverse axis of the calibration curve for the gas was recalculated as the concentration of the formaldehyde in solution using the following equation:

$\mathrm{C}_{\mathrm{FA} \mathrm{sol}}=\mathrm{Q} \times \mathrm{T} \times \mathrm{C}_{\mathrm{FAgas}} \times \operatorname{Dr} \times \rho$,

where $\mathrm{C}_{\mathrm{FA} \text { sol }}$ is the concentration of the formaldehyde in solution, $\mathrm{C}_{\mathrm{FA} \text { gas }}$ is the concentration of the formaldehyde gas, $\mathrm{Q}$ is the flow rate, $\mathrm{T}$ is the bubbling time, $\mathrm{Dr}$ is 1.08 , which is the relative vapor density of formaldehyde at $20^{\circ} \mathrm{C}$ (air $=1$ ), and $\rho$ is the density of air $\left(1.20 \mathrm{~kg} / \mathrm{m}^{3}\right)$. Note that the slope of the calibration curve for formaldehyde gas was less than that for formaldehyde in solution. This difference indicates that the formaldehyde gas was not completely dissolved in the assay solution. The amount of formaldehyde gas dissolved in the assay solution was estimated to be $67.8 \%$ based on the ratio of the slopes of the calibration curves for the gaseous and aqueous formaldehyde. 


\section{Conclusions}

We have demonstrated the detection of formaldehyde in water and gas using a highly sensitive and rapid sensor based on an enzymatic cycling system. FALDH was coupled to a cyclic $\mathrm{NAD}^{+}-\mathrm{NADH}$ reaction and the tetrazolium dye WST-8. The assay solution was optimized for the concentrations of WST-8, FALDH, and DI, as well as the reaction $\mathrm{pH}$ and time. The enzymatic cycling system can detect both solutions containing more than $15 \mathrm{ppb}$ formaldehyde within 3 min and gaseous samples containing more than 5 ppb formaldehyde within 5 min. Therefore, this system can detect the maximum permissible concentration of formaldehyde gas in residential buildings (80 ppb). In addition, the system has excellent selectivity as a gas recognition material due to the substrate specificity of FALDH. Finally, the concentration of formaldehyde can be determined based on the color change of WST- 8 formazan as the enzymatic cycling reaction proceeds, making it possible to downsize the device. Therefore, this system has the potential to be used for fabricating a formaldehyde analytical device with high portability and low cost. 


\section{Acknowledgments}

This research was supported partly by two grant programs, i.e., "The Local Collective Research Development Program” of the Japan Science and Technology Agency (JST) and the "Technological Strategies for Solving Urban Issues Program" of the Bureau of Industrial and Labor Affairs, Tokyo Metropolitan Government.

\section{References}

[1] L.E. Beane Freeman, A. Blair, J.H. Lubin, P.A. Stewart, R.B. Hayes, R.N. Hoover, M. Hauptmann, Mortality from lymphohematopoietic malignancies among workers in formaldehyde industries: the National Cancer Institute cohort, Journal of the National Cancer Institute 101 (2009) 751-761.

[2] World Health Organization, WHO guidelines for indoor air quality: selected pollutants (2010) 140-142.

[3] M. Kampa, E. Castanas, Human health effects of air pollution, Environmental Pollution 151 (2008) 362-367.

[4] I.M. Ritchie, R.G. Lehnen, Formaldehyde-related health complaints of residents living in mobile and conventional homes, American Journal of Public Health 77 (1987) $323-328$. 
[5] International Agency for Research on Cancer, A review of human carcinogens: chemical agents and related occupations $100 \mathrm{~F}$ (2012) 401-430.

[6] K.B. Rumchev, J.T. Spickett, M.K. Bulsara, M.R. Phillips, S.M. Stick, Domestic exposure to formaldehyde significantly increases the risk of asthma in young children, European Respiratory Journal 20 (2002) 403-408.

[7] J. Levin, K. Andersson, R. Linndahl, C. Nilsson, Determination of sub-part-per-million levels of formaldehyde in air using active or passive sampling on 2,4-dinitrophenylhydrazine-coated glass fibre filters and high-performance liquid chromatography, Analytical Chemistry 57 (1985) 1032-1035.

[8] M. Azuma, Y. Endo, T. Miyazaki, Y. Hikita, H. Ikeda, Y. Moriya, I. Hara, S. Araki, Efficacy of a detector tube method in formaldehyde measurement, Industrial Health-Kawasaki 41 (2003) 306-12.

[9] Y. Suzuki, N. Nakano, K. Suzuki, Portable sick house syndrome gas monitoring system based on novel colorimetric reagents for the highly selective and sensitive detection of formaldehyde, Environmental Science \& Technology 37 (2003) 5695-700.

[10] Q. Meng , T. Han , G. Wang , N. Zheng, Preparation of a natural dye doped Ormosil coating for the detection of formaldehyde in the optical gas sensor, Sensors and Actuators B: Chemical 192 (2014) 238-244. 
[11] A. Allouch M. Guglielmino P. Bernhardt C.A. Serra S.L. Calvé, Transportable, fast and high sensitive near real-time analyzers: Formaldehyde detection, Sensors and Actuators B: Chemical 181 (2013) 551-558.

[12] H. Kudo, M. Sawai, Y. Suzuki, X. Wang, T. Gessei, D. Takahashi, T. Arakawa, K. Mitsubayashi, Fiber-optic bio-sniffer (biochemical gas sensor) for high-selective monitoring of ethanol vapor using 335nm UV-LED, Sensors and Actuators B 147 (2010), 676-680.

[13] K. Mitsubayashi, G. Nishio, M. Sawai, T. Saito, H. Kudo, H. Saito, K. Otsuka, T. Noguer, J. L. Marty, A bio-sniffer stick with FALDH (formaldehyde dehydrogenase) for convenient analysis of gaseous formaldehyde, Sensors and Actuators B 130 (2008) $32-37$.

[14] H. Kudo, Y. Suzuki, T. Gessei, D. Takahashi, T. Arakawa, K. Mitsubayashi, Biochemical gas sensor (bio-sniffer) for ultrahigh-sensitive gaseous formaldehyde monitoring, Biosensors and Bioelectronics 26 (2010) 854-858.

[15] M.A. Ben, M. Gonchar, G. Gayda, S. Paryzhak, M.A. Maaref, N.R. Jaffrezic, Y. Korpan, Formaldehyde-sensitive sensor based on recombinant formaldehyde dehydrogenase using capacitance versus voltage measurements, Biosensors and Bioelectronics 22 (2007) 2790-2795. 
[16] M. Hämmerle, K. Hilgert, S. Achmann, R. Moos, Direct monitoring of organic vapours with amperometric enzyme gas sensors, Biosensors and Bioelectronics 25 (2010) 1521-1525.

[17] S. Nengsih, A.A. Umar, M.M. Salleh, M. Oyama, Detection of formaldehyde in water: A shape-effect on the plasmonic sensing properties of the gold nanoparticles, Sensors 12 (2012) 10309-10325.

[18] U.S. Akshath, A.C. Vinayaka, M.S. Thakur, Quantum dots as nano plug-in's for efficient NADH resonance energy routing, Biosensors and Bioelectronics, 38 (2012) $411-415$.

[19] Z.H. Lia, S.G. Suna, J.L. Marty, Design and characterization of methyl mercaptan biosensor using alcohol oxidase. Sensors and Actuators B: Chemical 192 (2014) 680-684.

[20] Y.I. Korpan, M.V. Gonchar, N.F. Starodub, A.A. Shulga, A.A. Sibirny, A.V. Elskaya, A cell biosensor specific for formaldehyde based on $\mathrm{pH}$-sensitive transistors coupled to methylotrophic yeast cells with genetically adjusted metabolism, Analytical Biochemistry 215 (1993) 216-222.

[21] J.J. Gooding, M. Haemmerle, E.A.H. Hall, An enzyme electrode with response independent of the thickness of the enzyme layer, Sensors and Actuators B: Chemical 
34 (1996) 516-523.

[22] M.J. Lobo, A.J. Miranda, P. Tunon, Amperometric biosensors based on NAD(P)-dependent dehydrogenase enzymes, Electroanalysis 9 (1997) 191-202.

[23] J.E. Aubin, Autofluorescence of viable cultured mammalian cells. Journal of Histochemistry \& Cytochemistry 27 (1979) 36-43.

[24] J.H.T. Luong, D.J. Carrier, On-line measurement of culture fluorescence during cultivation of Methylomonas mucosa, Applied Microbiology and Biotechnology 24 (1986) 65-70.

[25] J.K. Li, A.E. Humphrey, Use of fluorometry for monitoring and control of a bioreactor, Biotechnology and Bioengineering 37 (1991) 1043-1049.

[26] H.N. Kirkman, G.F. Gaetani, Regulation of glucose-6-phosphate dehydrogenase in human erythrocytes, Journal of Biological Chemistry 261 (1986) 4033-4038.

[27] M. Ishiyama, Y. Miyazono, K. Sasamoto, Y. Ohkura, K. Ueno, A highly water-soluble disulfonated tetrazolium salt as a chromogenic indicator for NADH as well as cell viability, Talanta 44 (1997) 1299-1305.

[28] L.H. Lam, T. Shimamura, S. Manabe, M. Ishiyama, H. Ukeda, Assay of angiotensin I-converting enzyme-inhibiting activity based on the detection of 3-hydroxybutyrate with water-soluble tetrazolium salt, Analytical Sciences, 24 (2008) 
$1057-1060$.

[29] W. Khampha, V. Meevootisom, S. Wiyakrutta, Spectrophotometric enzymatic cycling method using l-glutamate dehydrogenase and d-phenylglycine aminotransferase for determination of 1-glutamate in foods, Analytica Chimica Acta, 520 (2004) 133-139.

[30] A. Zhu, R. Romero, H. R. Petty, An enzymatic colorimetric assay for glucose-6-phosphate, Analytical Biochemistry, 419 (2011) 266-270.

[31] M. Ishiyama, Y. Miyazono, K Sasamoto, Y Ohkura, K Ueno, A highly water-soluble disulfonated tetrazolium salt as a chromogenic indicator for NADH as well as cell viability, Talanta 44 (1997) 1299-1305.

[32] M. Ando, T. Yoshimoto, S. Ogushi, K. Rikitake, S. Shibata, D. Tsuru, Formaldehyde dehydrogenase from Pseudomonas putida. Purification and some properties, Journal of Biochemistry 85 (1979) 1165-1172.

[33] F. Kaplan, P. Setlow, N.O. Kaplan, Purification and properties of a DPNH-TPNH diaphorase from Clostridium kluyverii, Archives of Biochemistry and Biophysics 132 (1969) 91-98.

[34] R.F. Branco, S.S. Silva, Contribution of Tris Buffer on Xylitol Enzymatic Production, Applied Biochemistry and Biotechnology 162 (2010) 1558-1563.

[35] E. Valero, F. Garcia-Carmona, Optimizing enzymatic cycling assays: 
spectrophotometric determination of low levels of pyruvate and L-Lactate, Analytical

Biochemistry, 239 (1996) 47-52. 


\section{Table}

Table 1. Average absorbance and relative standard deviation $(n=5)$ values for the assay solutions prepared after bubbling formaldehyde/air mixtures for 5 min.

Concentration (ppb) Average absorbance Relative standard deviation

\begin{tabular}{lll}
\hline 5 & 0.073 & $0.0047(6.43 \%)$ \\
10 & 0.10 & $00044(4.40 \%)$ \\
20 & 0.17 & $0.0016(1.00 \%)$ \\
50 & 0.38 & $0.0086(2.29 \%)$ \\
80 & 0.59 & $0.013(2.30 \%)$ \\
\hline
\end{tabular}


Figure captions

Figure 1. Schematic diagram of the system used for bubbling formaldehyde gas in the assay solution used with a biosensor. a) clean air unit, b) standard gas-generation system, c) mass-flow controller, d) assay solution.

Figure 2. $\mathrm{pH}$ dependence of the absorbance of assay solutions prepared using different buffer solutions.

Figure 3. Enzyme kinetic curves in borate $(\mathrm{pH} \mathrm{8.0,} \mathrm{8.5,} \mathrm{and} \mathrm{9.0)} \mathrm{and} \mathrm{tris-} \mathrm{HCl}(\mathrm{pH} \mathrm{8.0,}$ 8.5, and 9.0) buffer solutions.

Figure 4. a) Effect of DI concentration on the absorbance of assay solutions. b) Effect of FALDH concentration on the absorbance of assay solutions. c) Effect of WST-8 on the absorbance of assay solutions. 
Figure 5. Calibration curve for the enzymatic cycling system (formaldehyde concentrations ranging from 0.005 to $0.5 \mathrm{ppm}$ ) under the optimized conditions. Each data point is the average value for 5 measurements.

Figure 6. Selectivity of the biosensor for formaldehyde. Absorbance of assay solutions containing formaldehyde, formic acid, acetone, ethanol, and methanol.

Figure 7. a) Absorbance as a function of the volume of assay solutions after bubbling a formaldehyde/air mixture. b) Relationship between the bubbling time of a formaldehyde/air mixture and absorbance. c) Effect of the flow rate of the formaldehyde/air gas mixture on the enzymatic cycling reaction.

Figure 8. Calibration curve for assay solutions with different formaldehyde concentrations (5-80 ppb) prepared by bubbling formaldehyde/air gas mixtures. Each data point is the average value for 5 measurements.

Figure 9. Calibration curves for formaldehyde in water and gas. 
Figure(s)

Figure 1.

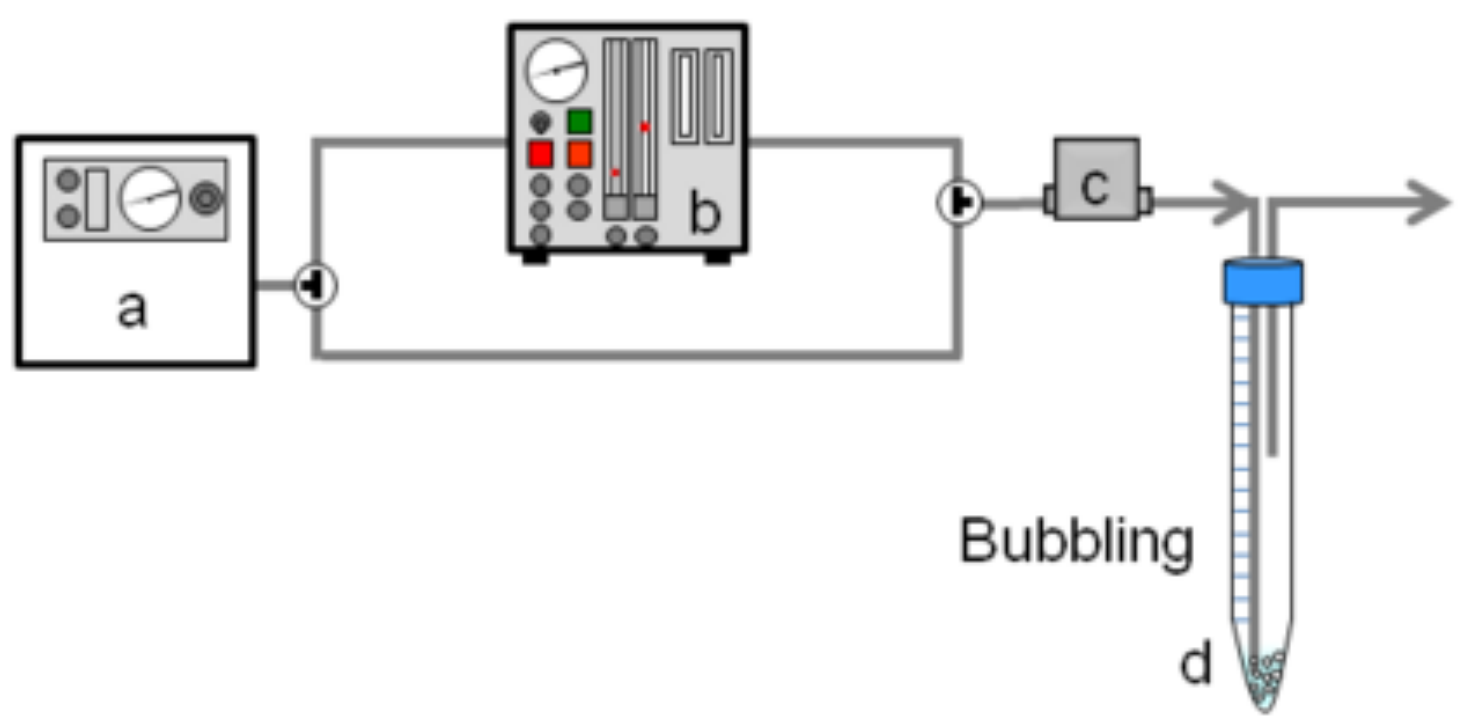


Figure 2.

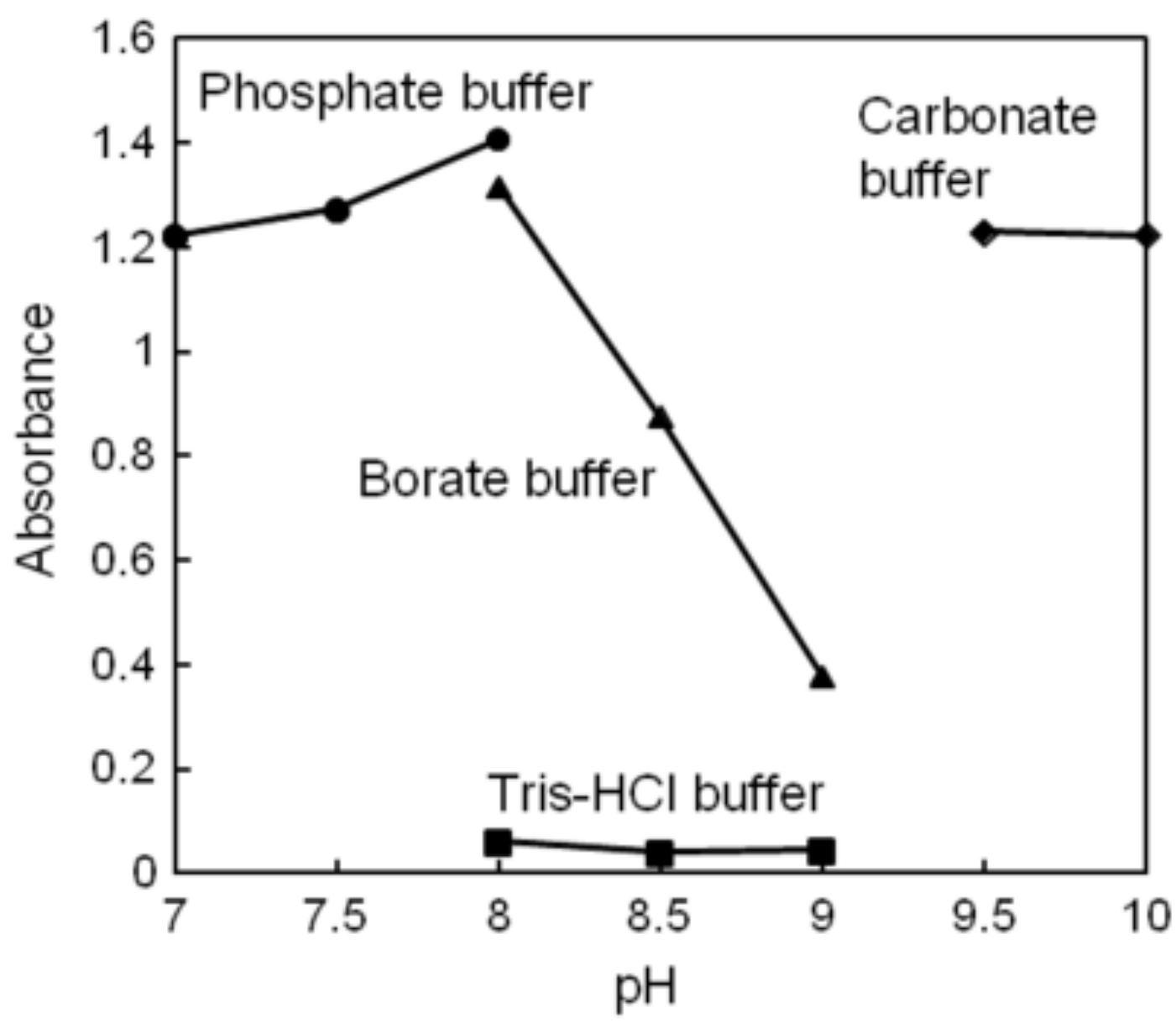




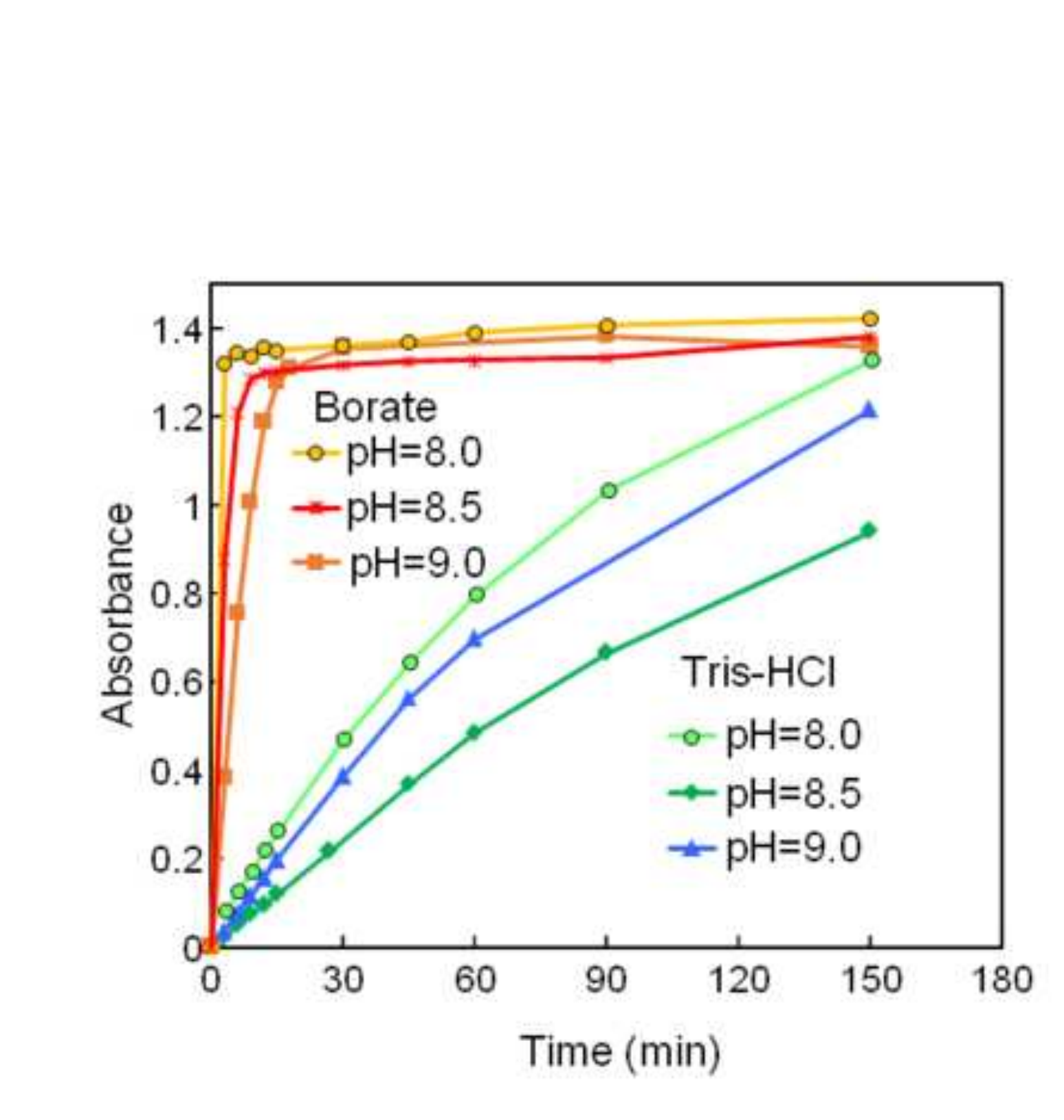

Figure(s)

.

.

\title{
Figure 3.

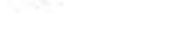

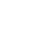

\begin{abstract}
(20)
\end{abstract}
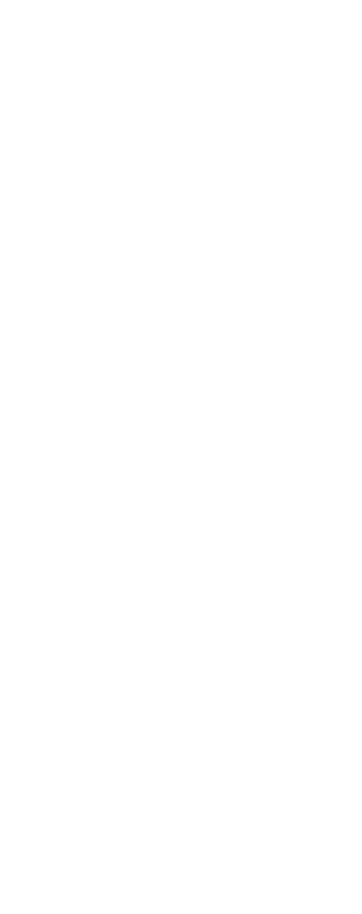
Figure(s)

Figure 4.
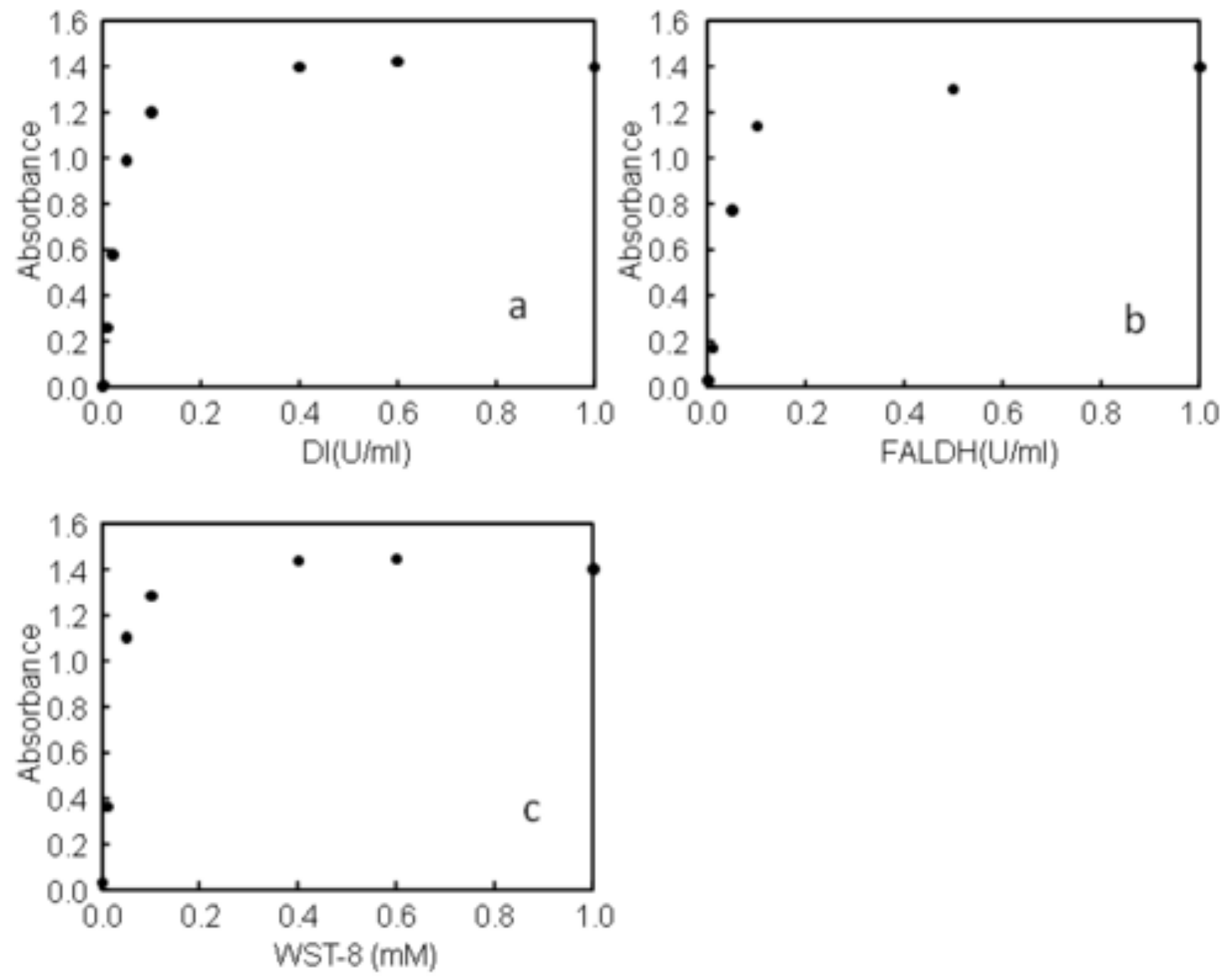


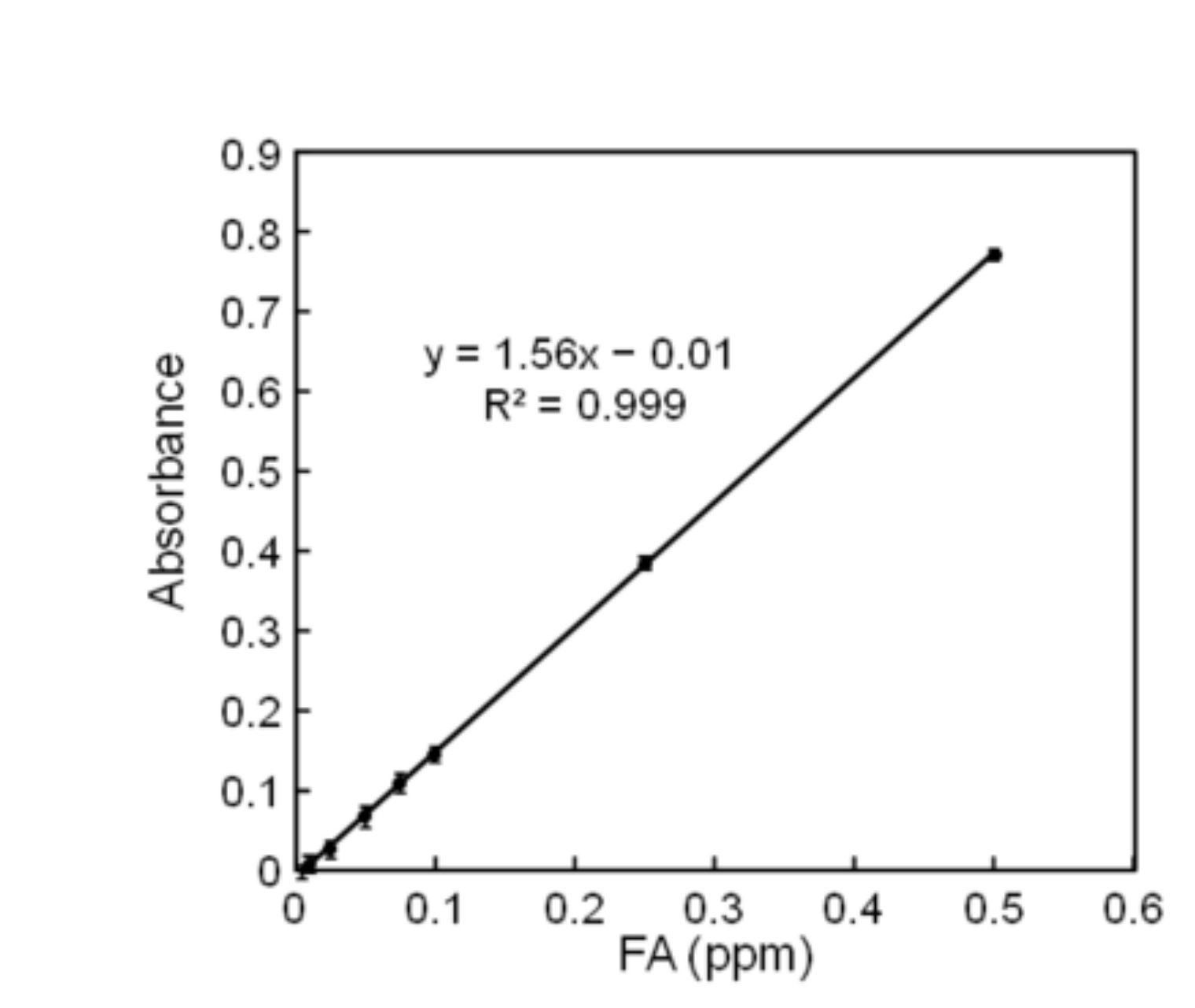

Figure(s)

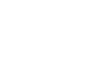

.

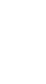

\section{Figure 5.}

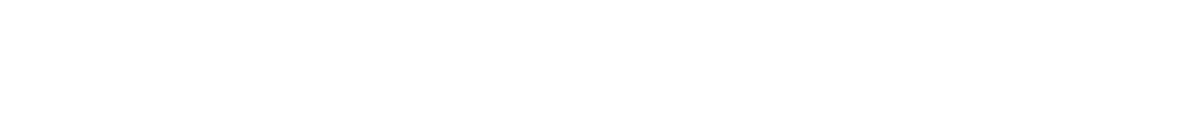

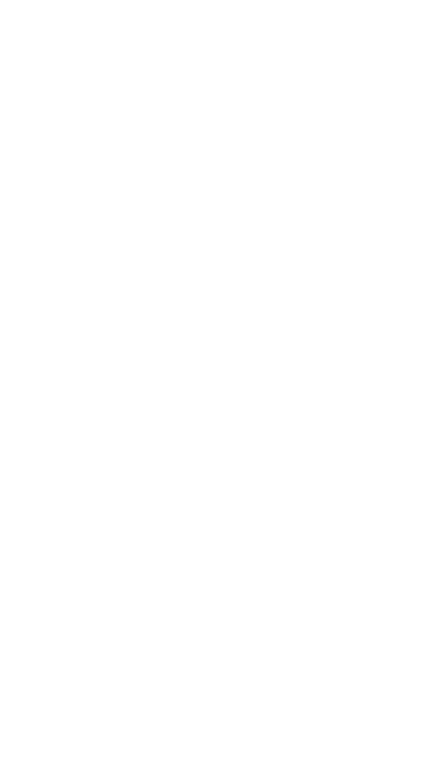


Figure 6.

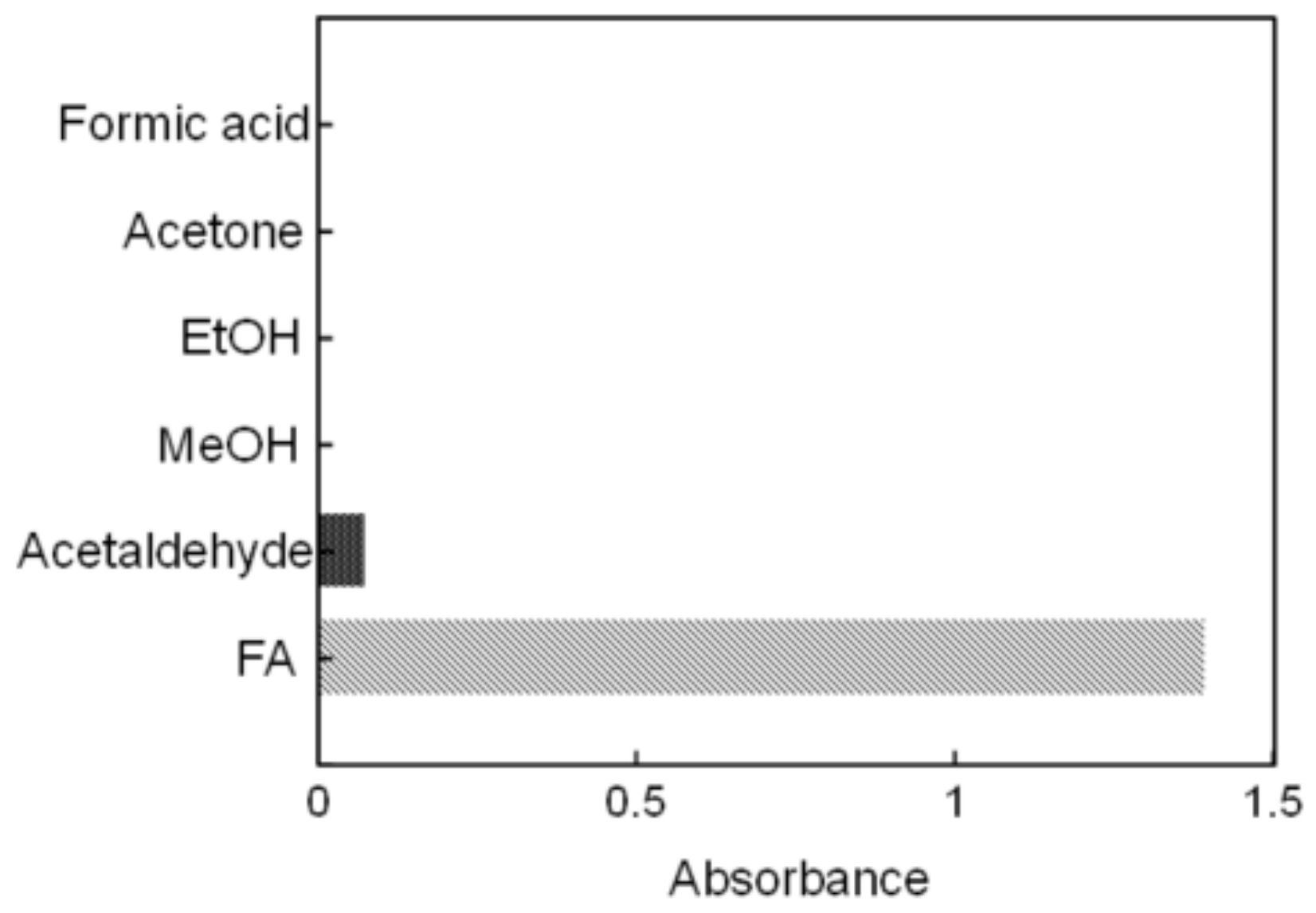

Figure(s) 
Figure 7.
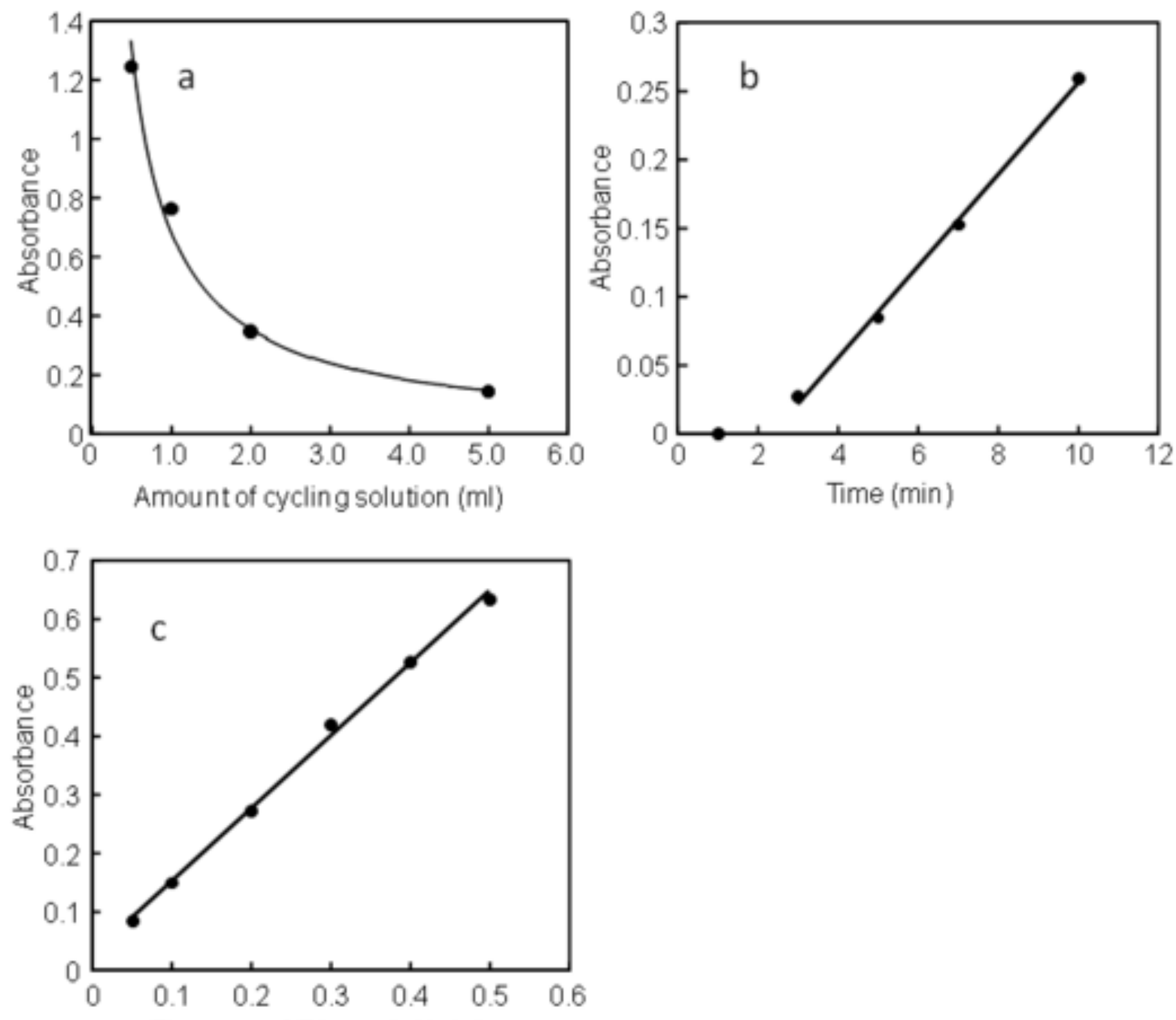

Flow rate of FA gas ( $\mathrm{ml} / \mathrm{min}$ ) 
Figure 8.

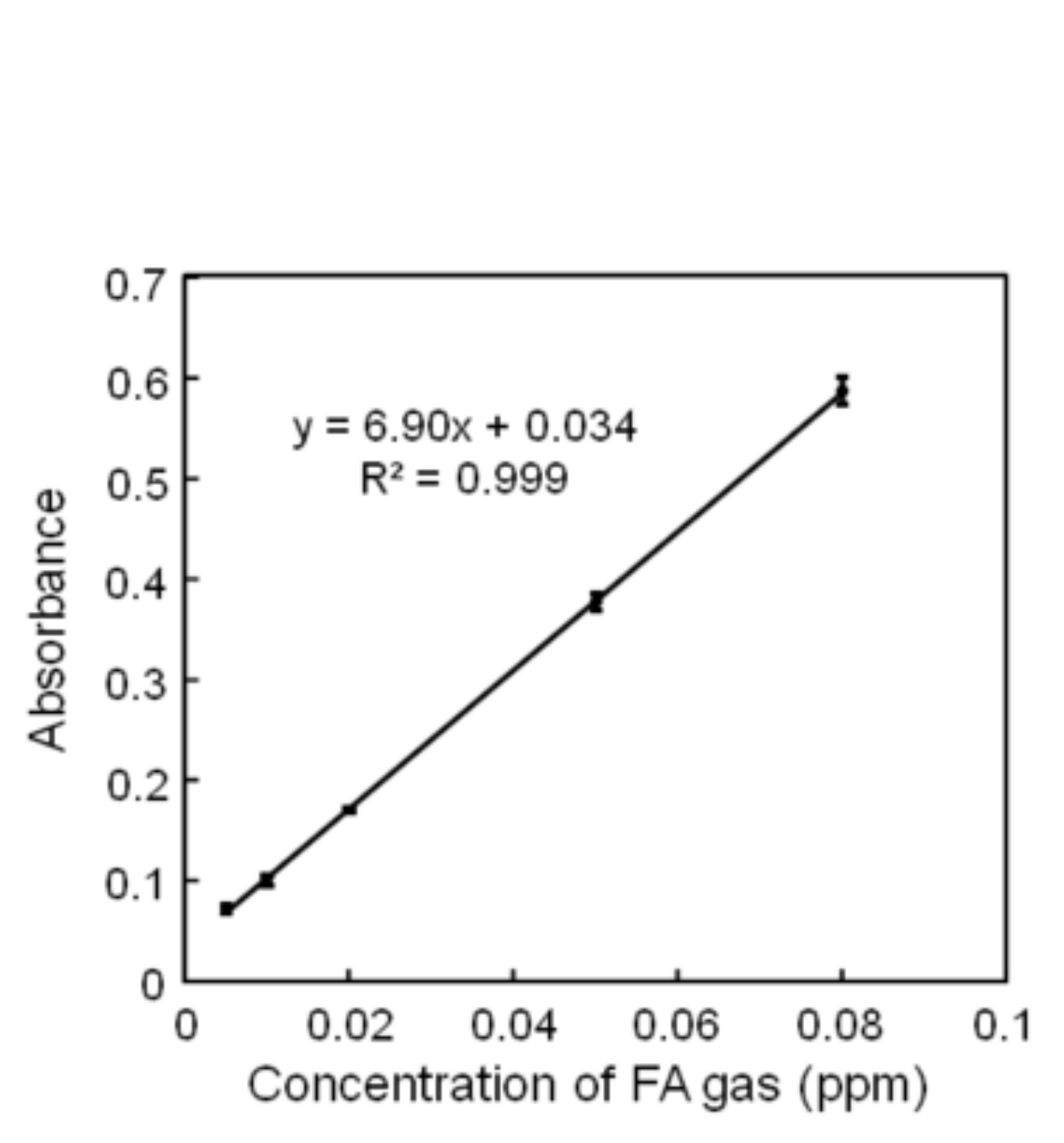

Figure(s)

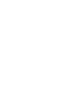

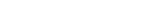
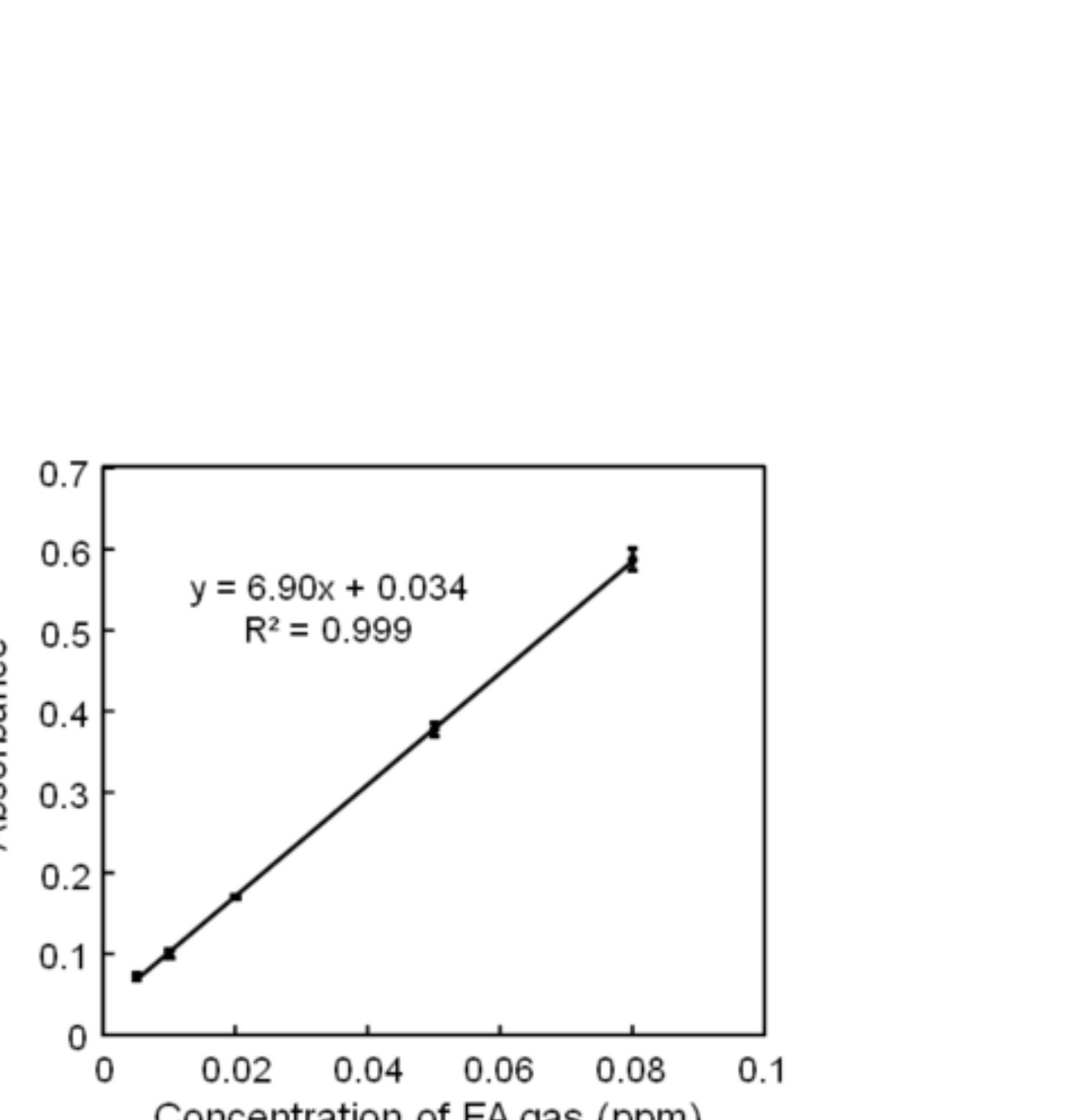
Figure 9.

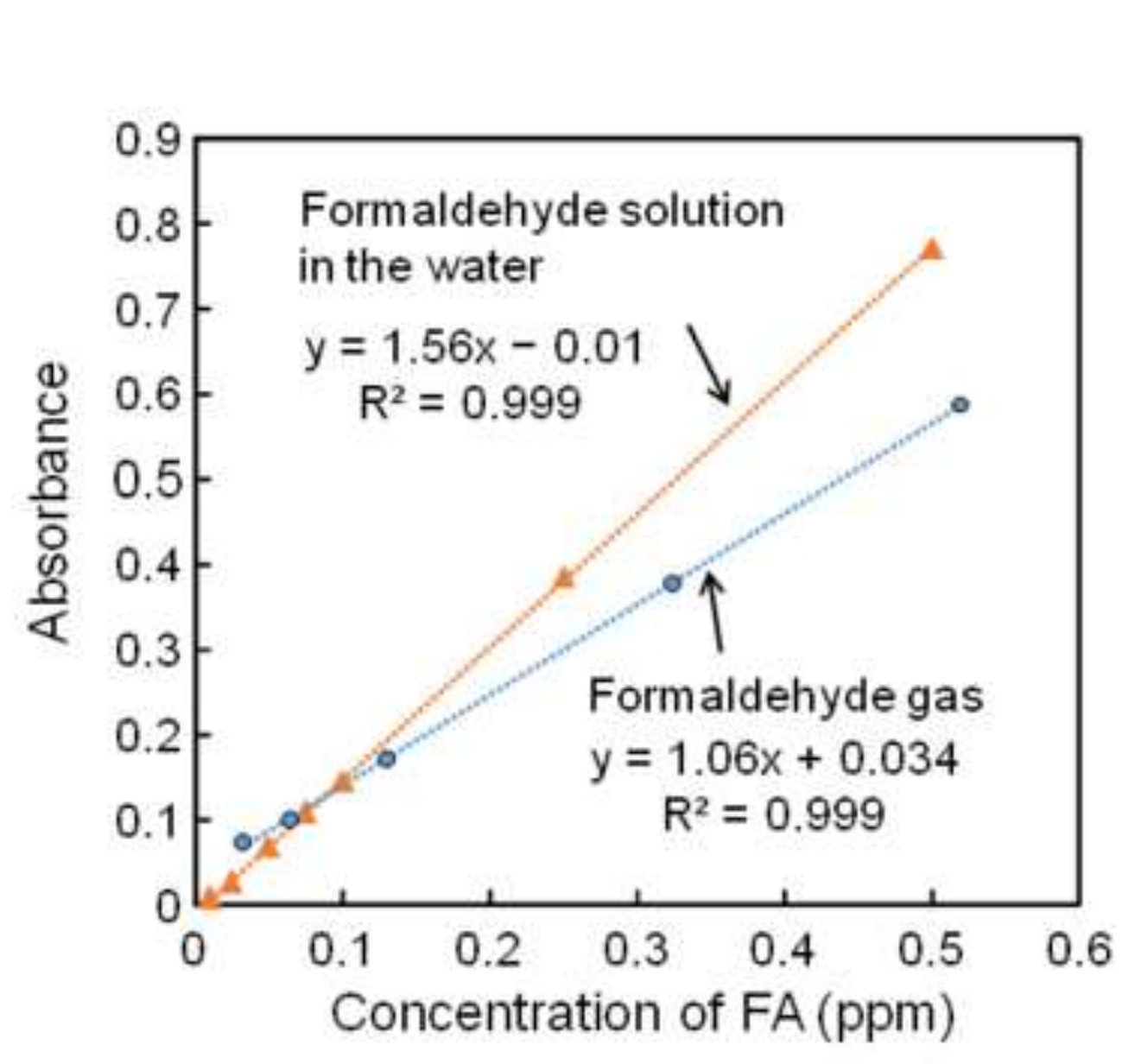

Figure(s) 